\title{
Older patients with early-stage oral cavity squamous cell carcinoma: outcomes for elderly patients aged 70 years or older
}

\author{
Fang-Yi Lin^, Chia-Chun Huang, Li-Chung Hung, Tsai-Wei Chou, Tung-Hao Chang, Jhen-Bin Lin \\ Department of Radiation Oncology, Changhua Christian Hospital, Changhua City, Taiwan \\ Contributions: (I) Conception and design: All authors; (II) Administrative support: TH Chang, JB Lin; (III) Provision of study materials or patients: \\ All authors; (IV) Collection and assembly of data: FY Lin, JB Lin; (V) Data analysis and interpretation: All authors; (VI) Manuscript writing: All \\ authors; (VII) Final approval of manuscript: All authors. \\ Correspondence to: Tung-Hao Chang, MD; Jhen-Bin Lin, MD. Department of Radiation Oncology, Changhua Christian Hospital, No. 135 Nanxiao \\ St., Changhua City, Changhua County 50050, Taiwan. Email: 81006@cch.org.tw; 146894@cch.org.tw.
}

\begin{abstract}
Background: The standard of care in operable oral cavity cancer is curative surgery followed by adjuvant therapy. However, adjuvant management of elderly patients with early-stage oral cavity squamous cell carcinoma (OCSCC) remains controversial. This study aims to identify predictors that will guide the adjuvant management in these patients.

Methods: We retrospectively analyzed 85 patients who were older than 70 years and had received surgical intervention for early-stage OCSCC in our institution between 2007 and 2015. The Kaplan-Meier analysis and log-rank test were used to estimate the disease-free survival (DFS), overall survival (OS). The predictor for DFS and OS was evaluated through COX regression and receiver operating characteristic (ROC) curve analysis.
\end{abstract}

Results: With a median follow-up time of 4.13 years, patients aged $<77.82$ years had better OS $(\mathrm{P}=0.032)$. Depth of invasion $\geq 3.25 \mathrm{~mm}$ was associated with poorer DFS $(\mathrm{P}=0.024)$.

Conclusions: Elderly patients with early-stage OCSCC might experience disease progression after surgery. Prospective trials are warranted to investigate the benefit of adjuvant treatment.

Keywords: Aged; oral cavity squamous cell carcinoma (OCSCC); treatment outcome

Received: 22 March 2020; Accepted: 16 July 2020; Published: 30 September 2020.

doi: $10.21037 /$ tro-20-33

View this article at: http://dx.doi.org/10.21037/tro-20-33

\section{Introduction}

Cancer of the oral cavity is one of the most common malignancies. There are an estimated 354,864 new cases of oral cavity cancer, and more than 177,000 oral cavity cancerrelated deaths annually (1). Surgery remains the primary standard of care in oral cavity cancer. The survival rate has been raised with the improvements in surgical techniques in combination with adjuvant radiation or chemoradiation therapy (2). A multidisciplinary approach ensures maximum disease control and minimal side effects (3). Adjuvant systemic therapy and radiotherapy is prescribed based on the independent risk of disease.

In the latest annual report from the Taiwanese cancer registry, the median age of diagnosis was 56 years for men and 63 years for women, while men took up $89 \%$ of the newly diagnosed cases. Overall, 786 (13.6\%) of the 5,790 patients newly diagnosed with oral cavity cancer were more than 70 years old (4). Elderly patients aged above 70 years are prone to toxicities in oncologic therapies and non-cancer related death. Standard therapies might be considered relatively aggressive to them and thus not be applied as often as to the younger cohort, considering performance status and tolerance of toxicity $(5,6)$. Although Taiwanese

$\wedge$ ORCID: 0000-0003-4473-165X. 
oncologists typically follow the National Comprehensive Cancer Network (NCCN) guidelines, the limited inclusion of the older population in clinical trials and the associated comorbidities preclude a uniform consensus regarding the optimal management (7). In elderly patients with earlystage oral cavity squamous cell carcinomas (OCSCC), there is yet no clear indication of adjuvant treatment.

As the life expectancy of the general population and the number of older patients increases, recognizing the predictors of outcome would allow clinicians to better assess the necessity of adjuvant treatment in these patients $(8,9)$. Some published literature suggests that in selected older patients, aggressive treatment can provide disease control and survival benefit similar to that for younger patients $(10,11)$. However, the adjuvant management of older patients with low risk oral cavity cancer remains to be investigated. Our goal was to identify predictors of disease-free survival (DFS) and overall survival (OS) among the older population with early-stage OCSCC after complete resection to aid in the consideration of adjuvant management.

We present the following article in accordance with the STROBE reporting checklist (available at http://dx.doi. org/10.21037/tro-20-33).

\section{Methods}

This research complied with the Helsinki Declaration (as revised in 2013). Our Institutional Review Board (IRB) approved the study (IRB No. 180503) and waived informed consents from the patients given all information which could possibly be used to identify the patients had been removed.

\section{Patients}

A retrospective chart review from our institutional cancer registry was performed to identify patients who were $>70$ years of age when diagnosed with pathological early stage (Tis/T1/T2, N0, M0) OCSCC between January 2007 and December 2015. Follow-up clinics and examinations were arranged based on the NCCN Guidelines of Head and Neck Cancers. The American Joint Committee on Cancer (AJCC) Cancer Staging System Seventh Edition was adopted. The exclusion criteria were a previous history of malignancy, synchronous malignancy, incomplete surgical excision of the primary tumor, and treatment delivered in other healthcare facilities.

\section{Data collection}

Data on relevant demographic characteristics, clinical and pathologic variables of each patient was abstracted. Unfavorable pathological findings (extra-nodal spread, positive resection margins, perineural involvement, or lymphovascular invasion) were defined based on the European Organization for Research and Treatment of Cancer Trial 22931 (12). The pathological adverse features score was defined as the number of unfavorable pathological findings. Pre-treatment hematologic parameters including white blood cell count, neutrophil percent, lymphocyte percent, monocyte percent, neutrophil to lymphocyte ratio and platelet to lymphocyte ratio were also collected. To assess comorbidity, the revised head and neck comorbidity index (HN-CCI) of each patient was also obtained (8). A local recurrence was defined as the reappearance of cancer at the initial primary site. A regional recurrence denoted tumor involving the regional lymph nodes. OS was defined as the time from the date of diagnostic biopsy until death. DFS was defined as the time from the date of initial surgery until recurrence or death.

\section{Treatment}

According to NCCN guidelines, surgery is the recommended initial treatment option for medically operable early-stage OCSCC. Postoperative adjuvant treatment options depend on whether adverse pathologic features are present. All patients in the current study underwent complete surgical excision without microscopic involved margin. Elective neck dissection was performed in 56 patients $(65.9 \%)$ and no nodal involvement was found (pN0). Twenty-nine patients had no clinical evidence of nodal involvement (cN0) and did not undergo elective nodal dissection. No major postoperative complication was noted.

Perioperative treatment included induction chemotherapy and/or adjuvant chemotherapy and/or postoperative radiation therapy. Adjuvant treatment was prescribed based on the independent risk of disease and the discussion with the patients regarding their performance status, comorbidities, and toxicity. The choice of chemotherapy regimen was at the physician's discretion. Oral form antineoplastic agents were more often selected than intravenous form agents to balance quality of life with treatment toxicity. Intensity modulated radiation therapy (IMRT) was used. 


\section{Statistics}

Predictors of relapse and survival were analyzed using COX regression. Factors marginally suggesting association with survival outcome $(\mathrm{P}<0.2)$ in the univariate COX regression analysis were chosen as variables in the multivariate $\mathrm{COX}$ regression analysis. The receiver operating characteristic (ROC) curve analysis was performed to detect the optimal cutoff value and the area under the ROC curve (AUC) in significant continuous variables. The Kaplan-Meier curve analysis and log-rank test was used to estimate the DFS and OS. Statistical significance was set as $\mathrm{P}<0.05$. The IBM ${ }^{\circledast}$ SPSS $^{\circledast}$ Statistics version 21 was used for all data analyses.

\section{Results}

Overall, there were 71 men and 14 women enrolled in the current study. The detail of enrollment diagram is provided in Figure S1. Table 1 summarizes the patient characteristics. There were $10(11.8 \%)$ patients receiving perioperative treatment. Five patients received chemotherapy alone and four patients received adjuvant radiotherapy only. One patient received both chemotherapy and radiotherapy. Oral tegafur/uracil was the choice of chemotherapy in all patients, with a starting dose of either one capsule three times daily or two capsules twice daily. The duration of chemotherapy depended on the tolerance of each patient (median: 28 days, range, $7-1,885$ days). Adjuvant radiation therapy was delivered using intensity-modulated radiotherapy (IMRT). Three patients received $200 \mathrm{cGy} /$ day for 5 days per week (total dose: 6,600 cGy) and one patient received $180 \mathrm{cGy} /$ day for 5 days per week (total dose: 6,120 cGy). One patient had incomplete radiotherapy with a delivered dose of $180 \mathrm{cGy} /$ day for 5 days per week (total dose: 2,160 cGy) because of pneumonia, and no chemotherapy was used in this case. The average age of patients was 73.8 and 75.9 years for those receiving perioperative treatment and those without perioperative treatment, respectively. The administration of perioperative treatment was not affected by the age at diagnosis $(\mathrm{P}=0.147)$. No parameter of blood test related to inflammation was found to be predictive of outcome (Tables S1-S3).

The median follow-up time was 4.13 years (range, $0.27-11.63$ years). During follow-up, there were 21 patients who developed local recurrence, four patients with regional recurrence in the lymph nodes, and one patient presenting both local and regional recurrence. Overall, disease relapse was observed in 26 patients. The average OS was 8.1 years (range, 7.0-9.2 years). The 3 - and 5 -year OS was $82.4 \%$ and $72.6 \%$. The average DFS was 7.34 years (range, 6.30 8.30 years). The 3 - and 5 -year DFS was $76.3 \%$ and $66.6 \%$.

Univariate analysis was performed to find the factors affecting the DFS and OS. Depth of invasion (DOI) (mm) significantly affected DFS $(\mathrm{P}=0.009)$. Age at diagnosis significantly affected $\mathrm{OS}(\mathrm{P}=0.005)$. In the multivariate COX regression analysis, we found DOI as the only predictor of DFS $[\mathrm{P}=0.037,95 \%$ confidence interval $(\mathrm{CI})$ : 1.008-1.298, B=0.134; hazard ratio $(\mathrm{HR})=1.144]$ after being adjusted by age, the Eastern Cooperative Oncology Group (ECOG) performance status, perioperative treatment, pathological adverse features, closet surgical margin, and monocyte count. Age at diagnosis affected OS after being adjusted by the ECOG performance status, pathological stage, body mass index (BMI), and DOI ( $\mathrm{P}=0.032,95 \% \mathrm{CI}$ : $1.008-1.202, \mathrm{~B}=0.096, \mathrm{HR}=1.101$ ).

The optimal value of DOI after ROC analysis was $3.25 \mathrm{~mm}$ (AUC $=0.663, \mathrm{P}=0.021$ ) (Figure S2). Patients with DOI $\geq 3.25 \mathrm{~mm}$ had decreased DFS ( $\mathrm{P}=0.024)$ (Table S4). To make the results more clinically applicable, we rounded the cut-off value to $4 \mathrm{~mm}(\mathrm{P}=0.051)$ instead of $3 \mathrm{~mm}(\mathrm{P}=0.813)$ for further analysis (Figure 1). The 3- and 5-year DFS was $90.3 \%$ and $76.9 \%$ in patients with DOI $<4 \mathrm{~mm}$, and $67.8 \%$ and $58.5 \%$ in patients with DOI $\geq 4 \mathrm{~mm}$, respectively.

The optimal cut-off point for age at diagnosis was 77.82 years ( $\mathrm{AUC}=0.63, \mathrm{P}=0.029$ ). Patients in the "younger old" group aged between 70 and 77.82 years presented better OS than the group of advanced age ( $\geq 77.82$ years) $(\mathrm{P}=0.008)$ (Figures 2,S3, Table S5). In the further analysis, we rounded the cutoff value to 78 years for the convenience of clinical practice. The 3- and 5-year OS was $91.5 \%$ and $83.1 \%$ in the younger group, and $61.5 \%$ and $56.4 \%$ in the advanced age group, respectively $(\mathrm{P}=0.026)$. The HN-CCI did not differ between both groups $(\mathrm{P}=0.54)$.

In patients who presented one or no pathological adverse risk feature, there was no significant benefit of DFS $(\mathrm{P}=0.414)$ and $\mathrm{OS}(\mathrm{P}=0.678)$ with perioperative therapy (Tables S6,S7).

\section{Discussion}

Older adults with early-stage OCSCC are rarely discussed in the literature and have been underrepresented in clinical trials. The optimal therapeutic strategy is still debated. In the current study, we found age and DOI predictive of outcome. The adjuvant management could be weighed in a 
Table 1 Patient characteristics

\begin{tabular}{|c|c|}
\hline Characteristic & Value \\
\hline \multicolumn{2}{|l|}{ Gender } \\
\hline Men & $71(83.5)$ \\
\hline Women & $14(16.5)$ \\
\hline Age (years), mean (range) & $75.7(70.0-90.5)$ \\
\hline BMI $\left(\mathrm{kg} / \mathrm{m}^{2}\right)$, mean (range) & $24.38(18.20-33.20)$ \\
\hline \multicolumn{2}{|l|}{ Pretreatment $\mathrm{ECOG}^{\ddagger}$} \\
\hline 0 & $59(69.4)$ \\
\hline 1 & $22(25.9)$ \\
\hline 2 & $4(4.7)$ \\
\hline \multicolumn{2}{|l|}{$\mathrm{HN}-\mathrm{CCl}$ Index } \\
\hline 0 & $35(41.2)$ \\
\hline 1 & $28(32.9)$ \\
\hline 2 & $16(18.8)$ \\
\hline 3 & $6(7.1)$ \\
\hline Smoking & $52(61.2)$ \\
\hline \multicolumn{2}{|l|}{ Pathological stage } \\
\hline 0 & $1(1.2)$ \\
\hline I & $53(62.4)$ \\
\hline II & $31(36.5)$ \\
\hline \multicolumn{2}{|l|}{ Pathological T stage } \\
\hline Tis & $1(1.2)$ \\
\hline $\mathrm{T} 1$ & $53(62.4)$ \\
\hline $\mathrm{T} 2$ & $31(36.5)$ \\
\hline Perioperative therapy & $10(11.8)$ \\
\hline Chemotherapy only & $5(5.9)$ \\
\hline Radiotherapy only & $4(4.7)$ \\
\hline Chemotherapy and radiotherapy & $1(1.2)$ \\
\hline Elective neck dissection & $56(65.9)$ \\
\hline \multicolumn{2}{|l|}{ Grade } \\
\hline 1 & $22(25.9)$ \\
\hline 2 & $61(71.8)$ \\
\hline 3 & $2(2.4)$ \\
\hline \multicolumn{2}{|l|}{ Primary site } \\
\hline Lip & $1(1.2)$ \\
\hline Tongue & $40(47.1)$ \\
\hline
\end{tabular}

Table 1 (continued)
Table 1 (continued)

\begin{tabular}{lc}
\hline Characteristic & Value \\
\hline Gum & $6(7.1)$ \\
Floor of mouth & $3(3.5)$ \\
Cheek mucosa & $32(37.6)$ \\
Retromolar area & $3(3.5)$ \\
Pathological adverse features & \\
Extra-nodal spread & $0(0)$ \\
Positive resection margin & $0(0)$ \\
Perineural involvement & $18(21.2)$ \\
Lymphovascular invasion & $6(7.1)$
\end{tabular}

BMI, body mass index; ECOG, the Eastern Cooperative Oncology Group performance status; $\mathrm{HN}-\mathrm{CCl}$, head and neck cancer comorbidity index.

multifactorial fashion.

\section{Survival}

In older patients with squamous carcinoma of the head and neck, the outcome of stage I/II disease could be similar to the younger cohort. The reported median OS in these patients ranges from 27 to 41.9 months, and the progression-free survival time (PFS) is 25 months for stage T1 tumor (13-15). The longer average OS and DFS observed in our study might result from the fact that we enrolled surgically fit patients. However, our data also suggested that patients in the younger old group demonstrated comparable 3 - and 5 -year OS of $91.8 \%$ and $83.8 \%$ with prospective trial with most patients under the age of 70 years (16).

Age

Advanced age is not only associated with increased risk of malignancies but is also an independent negative prognosticator for OS in older patients diagnosed with OCSCC $(14,17)$. Previous trials and studies of oral cavity cancers have either excluded patients older than 70 years of age or regarded those who are older than 70 as one cohort (12) (18-20). However, there is a relatively younger cohort, the" younger old", with better OS. The study of Gambotti and colleagues, which included 227 patients with oral cavity cancer from stage I to stage IV, identified age older than 79 years as a poor prognostic factor. The median OS for 


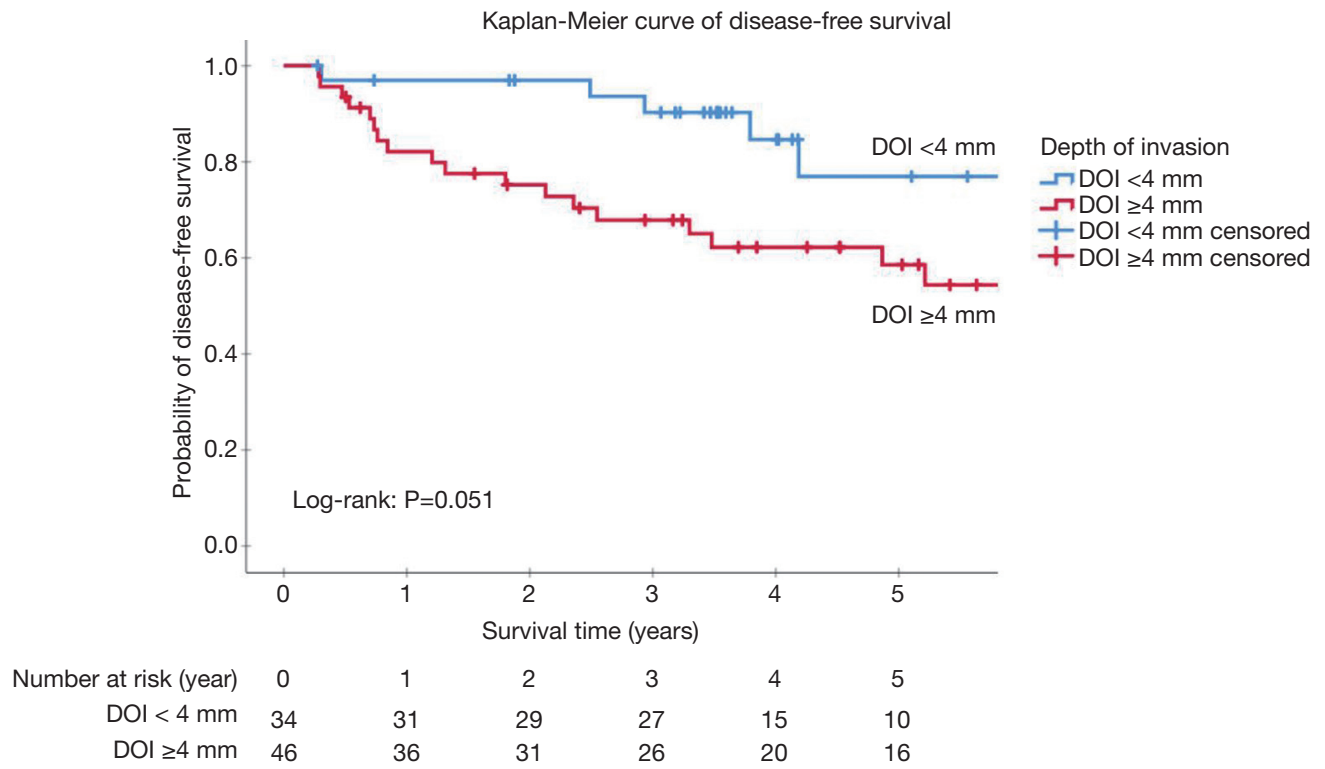

Figure 1 Impact of depth of invasion (DOI) on disease-free survival. Patients with DOI $\geq 4 \mathrm{~mm}$ present worse disease-free survival compared to patients with $\mathrm{DOI}<4 \mathrm{~mm}(\mathrm{P}=0.051)$.

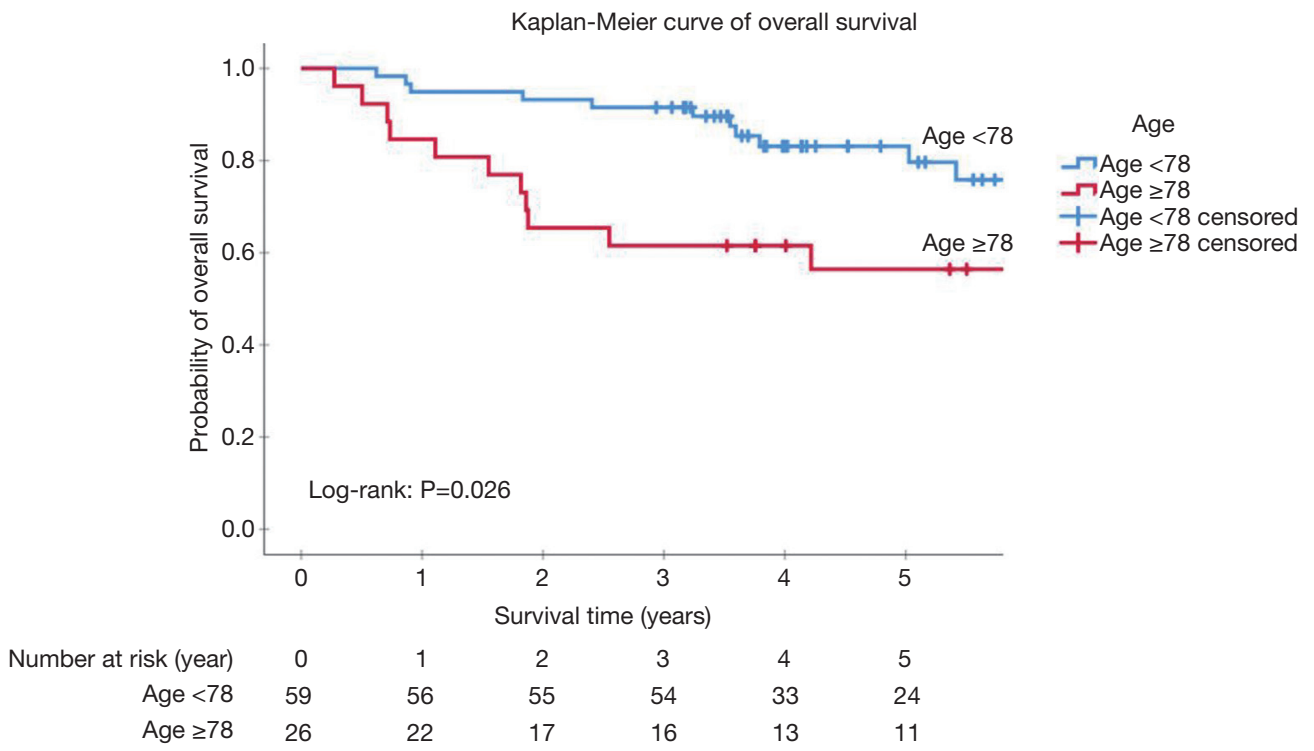

Figure 2 Impact of age on overall survival (OS). Patients with age $\geq 78$ present worse $O S$ than patients with age $<78$ ( $\mathrm{P}=0.026$ ).

patients older than 80 years treated with curative intention was 11.1 versus 23.7 months for patients 70 to 79 years of age (15). Significantly poorer OS and PFS was found in patients $\geq 85$ years of age from another study of 180 patients with OCSCC (21). We have also found the "advanced age" group presenting significantly poorer OS compared to the "younger old" group.

\section{DOI}

Kozak and colleagues evaluated the significance of increasing DOI as the sole risk factor for recurrence in patients with low-risk early-stage OCSCC, and their result confirms that increasing DOI is a marker for poorer PFS and OS (22). We included patients with similar low- 
risk characteristics and older than 70 years. DOI is an independent negative predictor for DFS, yet it does not affect $O S$ in multivariate analysis.

\section{Pathological adverse risk features}

Pathological adverse risk features are known to be associated with disease progression and overall prognosis. Yet the role of adjuvant treatment in the presence of adverse histologic features in early-stage oral cavity cancer is still debated (23-25). Among elderly patients with earlystage OCSCC, we found no significant benefit of DFS and OS with perioperative therapy in patients presenting one or no pathological adverse risk feature. The study of Subramaniam and colleagues showed that presenting more than one pathological risk factor indicated higher possibility of recurrence and thus patients are likely to benefit from adjuvant radiotherapy (25). The other study demonstrated that for patients with OCSCC and at least two minor prognostic factors without any major risk factor, postoperative radiotherapy, or concurrent chemoradiation therapy yielded significantly better 5-year locoregional control, DFS, and OS, compared to the surgery only group (26). The pros and cons of adjuvant treatment among older patients should be discussed, especially with those who are at higher risk of relapse.

\section{Comorbidity}

Comorbidity is frequently seen in the elderly with HNSCC and negatively impacts survival (27). The HN-CCI, developed by Bøje and colleagues, was adopted to assess comorbidity in our study (8). Given that the eligible patients in our study were suitable for primary surgical intervention, the ECOG performance status and the HN-CCI were $\leq 1$ in $95.3 \%$ and $74.1 \%$ of all patients, respectively. This is reflected in the better survival rate and little impact of comorbidity on the outcome.

While several authors demonstrated that the main predictive factors of mortality and complications were comorbidities and length of surgery, regardless of the age of the patient, our findings suggest that in elderly patients with early-stage OCSCC suitable for radical surgery, OS deteriorates with advanced age $(15,28-30)$. Nevertheless, our report still supports the use of surgery as the local intervention in suitable older patients because of the better survival outcome compared to previous studies.

\section{Perioperative therapy}

Data reported by Chen and colleagues showed no benefit in OS or locoregional recurrence with adjuvant therapy in older patients with OCSCC with adverse features, even though $48 \%$ of patients who met the indications for adjuvant therapy did not receive it (21). The other study also showed no survival difference between $>70$ and $\leq 70$ years of age while significantly more patients $>70$ years old could not receive or complete appropriate adjuvant therapy (31). Overall, perioperative therapy was used in $10(11.8 \%)$ of our patients and this did not affect either OS or DFS. Future prospective research is warranted to further clarify the role of adjuvant therapy in the elderly.

\section{Pre-treatment neutrophil-to-lymphocyte ratio (NLR), platelet-to-lymphocyte ratio (PLR)}

Although studies on the efficacy of treatment when stratified by NLR, PLR and inflammatory biomarkers have reported the potential value of predicting survival in cancers of the head and neck, it has not yet been thoroughly studied based on stratification of disease stage and risk. Counts of neutrophil and lymphocyte could be affected by factors including comorbidities and medications administered $(32,33)$. Our study focuses on patients with early-stage OCSCC receiving primarily surgical intervention and our findings do not show predictive values of NLR and PLR regarding DFS and OS.

\section{Limitations}

There were several limitations in this retrospective study with a relatively small sample size. Most participants had good performance status to receive primary surgical intervention. The results might not be implied to patients who are not candidates for surgery or with incomplete resection. Second, a comprehensive geriatric assessment (CGA), a tool which allowed clinicians to evaluate the balance of benefits and harms of performing or omitting specific oncologic interventions, was not feasible retrospectively $(34,35)$. Finally, the relatively lower proportion of patients receiving perioperative therapy might compromise the conclusive result among those with 
multiple pathological adverse risk features.

\section{Conclusions}

In conclusion, the current study has shown that the outcome of the surgically fit older population with earlystage OCSCC could be further stratified by age as well as by pathological adverse features. Prospective studies are warranted to investigate the benefit of adjuvant treatment.

\section{Acknowledgments}

We thank the physicians who performed the surgeries and the assistance from our Department of Statistical Sciences and Epidemiology.

Funding: None.

\section{Footnote}

Reporting Checklist: The authors have completed the STROBE reporting checklist. Available at http://dx.doi. org/10.21037/tro-20-33

Conflicts of Interest: All authors have completed the ICMJE uniform disclosure form (available at http://dx.doi. org/10.21037/tro-20-33). The authors have no conflicts of interest to declare.

Ethical Statement: The authors are accountable for all aspects of the work in ensuring that questions related to the accuracy or integrity of any part of the work are appropriately investigated and resolved. This research complied with the Helsinki Declaration (as revised in 2013). Our Institutional Review Board (IRB) approved the study (IRB No. 180503) and waived informed consents from the patients given all information which could possibly be used to identify the patients had been removed.

Open Access Statement: This is an Open Access article distributed in accordance with the Creative Commons Attribution-NonCommercial-NoDerivs 4.0 International License (CC BY-NC-ND 4.0), which permits the noncommercial replication and distribution of the article with the strict proviso that no changes or edits are made and the original work is properly cited (including links to both the formal publication through the relevant DOI and the license). See: https://creativecommons.org/licenses/by-nc-nd/4.0/.

\section{References}

1. Bray F, Ferlay J, Soerjomataram I, et al. Global cancer statistics 2018: GLOBOCAN estimates of incidence and mortality worldwide for 36 cancers in 185 countries. CA Cancer J Clin 2018;68:394-424.

2. Pulte $\mathrm{D}$, Brenner H. Changes in survival in head and neck cancers in the late 20th and early 21 st century: a period analysis. Oncologist 2010;15:994-1001.

3. Montero PH, Patel SG. Cancer of the oral cavity. Surg Oncol Clin N Am 2015;24:491-508.

4. Cancer Registry Annual Report, 2017. Taiwan: Health Promotion Administration (HPA), Ministry of Health and Welfare, 2019.

5. Pollom EL, Chin AL, Lee NY, et al. Patterns of Care in Adjuvant Therapy for Resected Oral Cavity Squamous Cell Cancer in Elderly Patients. Int J Radiat Oncol Biol Phys 2017;98:758-66.

6. Craigs CL, Bennett MI, Hurlow A, et al. Older age is associated with less cancer treatment: a longitudinal study of English cancer patients. Age Ageing 2018;47:833-40.

7. Shia BC, Qin L, Lin KC, et al. Outcomes for Elderly Patients Aged 70 to 80 Years or Older with Locally Advanced Oral Cavity Squamous Cell Carcinoma: A Propensity Score-Matched, Nationwide, Oldest Old Patient-Based Cohort Study. Cancers (Basel) 2020;12:258.

8. Bøje CR, Dalton SO, Primdahl H, et al. Evaluation of comorbidity in 9388 head and neck cancer patients: a national cohort study from the DAHANCA database. Radiother Oncol 2014;110:91-7.

9. Parry JL, Hall PS, Young J. New horizons in systemic anticancer therapy in older people. Age Ageing 2018;47:340-8.

10. Sarini J, Fournier C, Lefebvre JL, et al. Head and neck squamous cell carcinoma in elderly patients: a long-term retrospective review of 273 cases. Arch Otolaryngol Head Neck Surg 2001;127:1089-92.

11. Chen RC, Royce TJ, Extermann M, et al. Impact of age and comorbidity on treatment and outcomes in elderly cancer patients. Semin Radiat Oncol 2012;22:265-71.

12. Bernier J, Domenge C, Ozsahin M, et al. Postoperative irradiation with or without concomitant chemotherapy for locally advanced head and neck cancer. N Engl J Med 2004;350:1945-52.

13. Italiano A, Ortholan C, Dassonville O, et al. Head and neck squamous cell carcinoma in patients aged $>$ or $=80$ years: patterns of care and survival. Cancer 2008;113:3160-8.

14. Ortholan C, Lusinchi A, Italiano A, et al. Oral cavity 
squamous cell carcinoma in 260 patients aged 80years or more. Radiother Oncol 2009;93:516-23.

15. Gambotti L, Schwob E, Schouman T, et al. Are elderly patients presenting with squamous cell carcinoma of the oral cavity given the appropriate treatment? Surg Oncol 2018;27:715-21.

16. D'Cruz AK, Vaish R, Kapre N, et al. Elective versus Therapeutic Neck Dissection in Node-Negative Oral Cancer. N Engl J Med 2015;373:521-9.

17. Jones AS, Beasley N, Houghton D, et al. The effects of age on survival and other parameters in squamous cell carcinoma of the oral cavity, pharynx and larynx. Clin Otolaryngol Allied Sci 1998;23:51-6.

18. Bernier J, Cooper JS, Pajak TF, et al. Defining risk levels in locally advanced head and neck cancers: a comparative analysis of concurrent postoperative radiation plus chemotherapy trials of the EORTC (\#22931) and RTOG (\# 9501). Head Neck 2005;27:843-50.

19. Singh H, Kanapuru B, Smith C, et al. FDA analysis of enrollment of older adults in clinical trials for cancer drug registration: A 10-year experience by the U.S. Food and Drug Administration. J Clin Oncol 2017;35:abstr 10009.

20. Cooper JS, Pajak TF, Forastiere AA, et al. Postoperative concurrent radiotherapy and chemotherapy for high-risk squamous-cell carcinoma of the head and neck. N Engl J Med 2004;350:1937-44.

21. Chen JJ, Shah JL, Harris JP, et al. Clinical Outcomes in Elderly Patients Treated for Oral Cavity Squamous Cell Carcinoma. Int J Radiat Oncol Biol Phys 2017;98:775-83.

22. Kozak MM, Shah J, Chen M, et al. Depth of invasion alone as a prognostic factor in low-risk early-stage oral cavity carcinoma. Laryngoscope 2019;129:2082-6.

23. Liu SA, Wang CC, Jiang RS, et al. Pathological features and their prognostic impacts on oral cavity cancer patients among different subsites - A singe institute's experience in Taiwan. Sci Rep 2017;7:7451.

24. Liu T, Chua B, Batstone M. Postoperative Radiotherapy for Oral Squamous Cell Carcinoma With Histologic Risk Factors: Are We Over-Treating? J Oral Maxillofac Surg 2018;76:1565-70.

25. Subramaniam N, Balasubramanian D, Murthy S, et al.

doi: $10.21037 /$ tro-20-33

Cite this article as: Lin FY, Huang CC, Hung LC, Chou TW, Chang TH, Lin JB. Older patients with early-stage oral cavity squamous cell carcinoma: outcomes for elderly patients aged 70 years or older. Ther Radiol Oncol 2020;4:15.
Adverse pathologic features in early oral squamous cell carcinoma and the role of postoperative radiotherapy-a review. Oral Surg Oral Med Oral Pathol Oral Radiol 2017;124:24-31.

26. Chen WC, Lai CH, Fang CC, et al. Identification of HighRisk Subgroups of Patients With Oral Cavity Cancer in Need of Postoperative Adjuvant Radiotherapy or ChemoRadiotherapy. Medicine (Baltimore) 2016;95:e3770.

27. Sanabria A, Carvalho AL, Vartanian JG, et al. Comorbidity is a prognostic factor in elderly patients with head and neck cancer. Ann Surg Oncol 2007;14:1449-57.

28. Pelczar BT, Weed HG, Schuller DE, et al. Identifying high-risk patients before head and neck oncologic surgery. Arch Otolaryngol Head Neck Surg 1993;119:861-4.

29. Farwell DG, Reilly DF, Weymuller EA Jr, et al. Predictors of perioperative complications in head and neck patients. Arch Otolaryngol Head Neck Surg 2002;128:505-11.

30. Ferrier MB, Spuesens EB, Le Cessie S, et al. Comorbidity as a major risk factor for mortality and complications in head and neck surgery. Arch Otolaryngol Head Neck Surg 2005;131:27-32.

31. Malik A, Mishra A, Chopda P, et al. Impact of age on elderly patients with oral cancer. Eur Arch Otorhinolaryngol 2019;276:223-31.

32. Nakashima H, Matsuoka Y, Yoshida R, et al. Pretreatment neutrophil to lymphocyte ratio predicts the chemoradiotherapy outcome and survival in patients with oral squamous cell carcinoma: a retrospective study. BMC Cancer 2016;16:41.

33. Rachidi S, Wallace K, Wrangle JM, et al. Neutrophil-tolymphocyte ratio and overall survival in all sites of head and neck squamous cell carcinoma. Head Neck 2016;38 Suppl 1:E1068-74.

34. Wildiers H, Heeren P, Puts M, et al. International Society of Geriatric Oncology consensus on geriatric assessment in older patients with cancer. J Clin Oncol 2014;32:2595-603.

35. Maggiore R, Zumsteg ZS, BrintzenhofeSzoc K, et al. The Older Adult With Locoregionally Advanced Head and Neck Squamous Cell Carcinoma: Knowledge Gaps and Future Direction in Assessment and Treatment. Int J Radiat Oncol Biol Phys 2017;98:868-83. 
From 2007-01-01 to 2015-12-31, there were 5,464 patients diagnosed with

head and neck cancers registered in our institutional database.

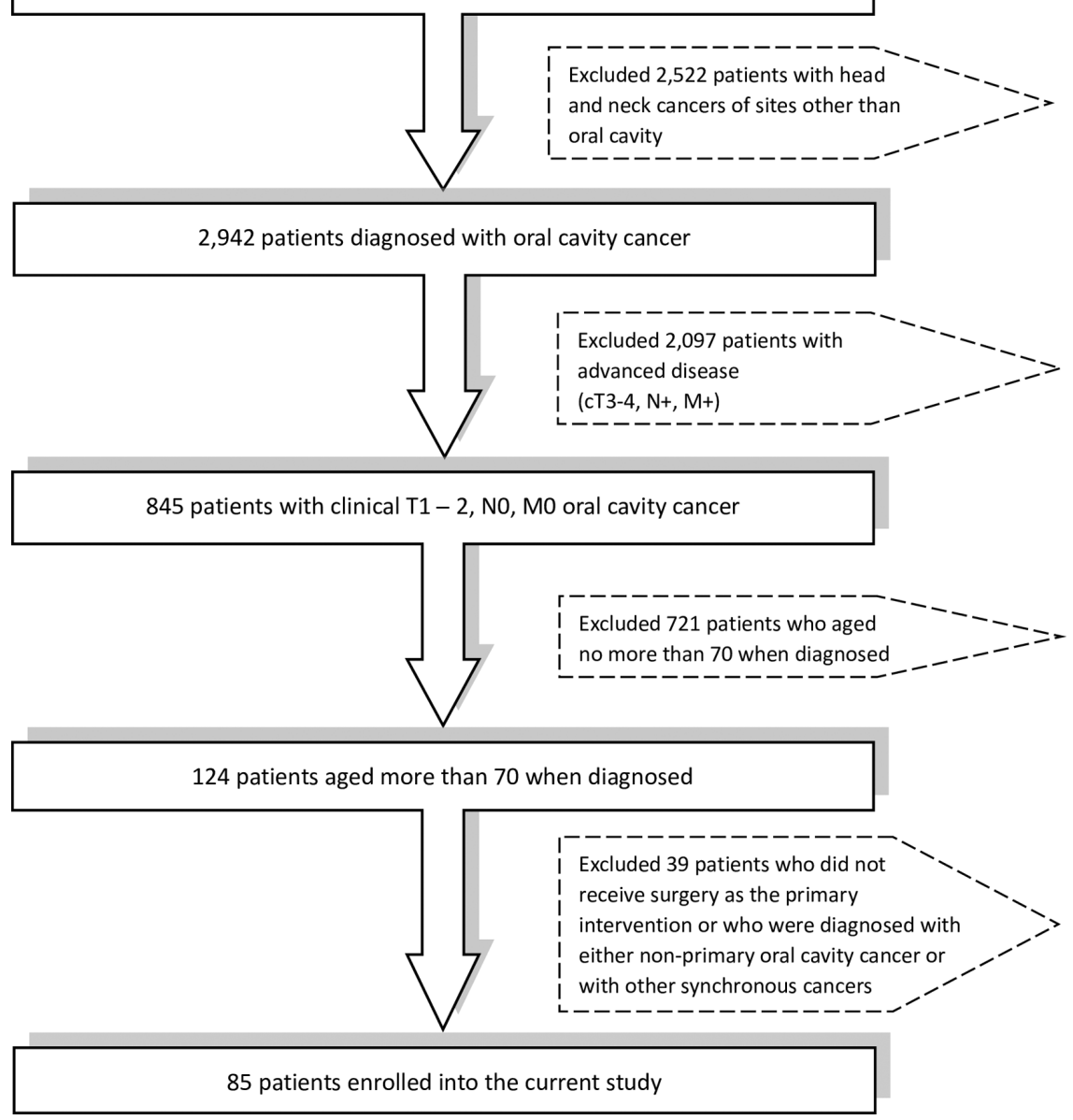

Figure S1 Enrollment diagram of 5,464 patients. From January 2007 to December 2015, there were 5,464 patients diagnosed with head and neck cancers registered in our institutional database. Among the 5,464 patients, 2,942 patients were diagnosed with oral cavity cancer and 845 patients of them presented early-stage (clinical T1-2, N0, M0) disease. There were 124 patients of early-stage disease older than 70 when diagnosed. Thirty-nine patients were then excluded due to nonprimary surgical intervention, with synchronous cancers, or with nonprimary oral cavity cancer. Eighty-five patients were enrolled into the current study. 
Table S1 Univariate and multivariate COX regression analysis of predictors of disease-free survival

\begin{tabular}{|c|c|c|c|c|c|c|c|c|}
\hline \multirow{2}{*}{ Characteristics } & \multicolumn{4}{|c|}{ Univariate } & \multicolumn{4}{|c|}{ Multivariate } \\
\hline & $\begin{array}{l}\text { Hazard } \\
\text { ratio }\end{array}$ & Lower limit & Upper limit & $P$ value & $\begin{array}{l}\text { Hazard } \\
\text { ratio }\end{array}$ & Lower limit & Upper limit & $P$ value \\
\hline Gender & 1.570 & 0.628 & 3.923 & 0.335 & - & - & - & - \\
\hline Age (years) & 1.078 & 0.987 & 1.176 & 0.094 & 1.064 & 0.957 & 1.183 & 0.250 \\
\hline $\mathrm{HN}-\mathrm{CCl}$ & 0.827 & 0.529 & 1.293 & 0.406 & - & - & - & - \\
\hline ECOG & 0.535 & 0.232 & 1.234 & 0.142 & 0.585 & 0.245 & 1.398 & 0.228 \\
\hline Pathological stage & 0.920 & 0.410 & 2.064 & 0.841 & - & - & - & - \\
\hline $\begin{array}{l}\text { Perioperative therapy } \\
\text { (including chemotherapy } \\
\text { and radiotherapy) }\end{array}$ & 0.217 & 0.029 & 1.602 & 0.134 & 0.133 & 0.016 & 1.138 & 0.066 \\
\hline $\begin{array}{l}\text { Moderately differentiated } \\
\text { vs. poorly differentiated }\end{array}$ & $8,904.330$ & 0 & $1.671 \mathrm{E}+100$ & 0.936 & - & - & - & - \\
\hline $\begin{array}{l}\text { Moderately differentiate } \\
\text { vs. well differentiated }\end{array}$ & 1.171 & 0.491 & 2.795 & 0.722 & - & - & - & - \\
\hline BMI $\left(\mathrm{kg} / \mathrm{m}^{2}\right)$ & 0.998 & 0.886 & 1.125 & 0.976 & - & - & - & - \\
\hline $\begin{array}{l}\text { Pathological adverse } \\
\text { features score }\end{array}$ & 1.897 & 0.951 & 3.783 & 0.069 & 1.089 & 0.455 & 2.607 & 0.847 \\
\hline $\begin{array}{l}\text { Closet surgical margin } \\
(\mathrm{mm})\end{array}$ & 0.909 & 0.802 & 1.031 & 0.139 & 0.915 & 0.783 & 1.070 & 0.266 \\
\hline Monocyte (\%) & 1.122 & 0.955 & 1.318 & 0.161 & 1.108 & 0.908 & 1.352 & 0.311 \\
\hline NLR & 1.087 & 0.927 & 1.275 & 0.302 & - & - & - & - \\
\hline
\end{tabular}

The depth of invasion (DOI) correlates with disease-free survival in the univariate COX regression analysis $(P=0.009)$; the factors of marginal significance include the age at diagnosis, ECOG, perioperative therapy, pathological adverse features score, the closet surgical margin, and monocyte count. The multivariate COX regression analysis includes factors marginally suggesting association with survival outcome $(P<0.2)$ in the univariate COX regression analysis. Depth of Invasion $(\mathrm{mm})$ correlates with disease-free survival $(P=0.037)$. $\mathrm{HN}$ $\mathrm{CCl}$, head and neck cancer comorbidity index; ECOG, the Eastern Cooperative Oncology Group performance status; BMI, body mass index; WBC, white blood cell; NLR, neutrophil-to-lymphocyte ratio. 
Table S2 Univariate and multivariate COX regression analysis of predictors of overall survival

\begin{tabular}{|c|c|c|c|c|c|c|c|c|}
\hline \multirow{2}{*}{ Characteristics } & \multicolumn{4}{|c|}{ Univariate } & \multicolumn{4}{|c|}{ Multivariate } \\
\hline & $\begin{array}{l}\text { Hazard } \\
\text { ratio }\end{array}$ & Lower limit & Upper limit & $P$ value & $\begin{array}{l}\text { Hazard } \\
\text { ratio }\end{array}$ & Lower limit & Upper limit & $P$ value \\
\hline Gender & 1.500 & 0.597 & 3.766 & 0.388 & - & - & - & - \\
\hline Age (years) & 1.131 & 1.038 & 1.233 & 0.005 & 1.101 & 1.008 & 1.202 & 0.032 \\
\hline $\mathrm{HN}-\mathrm{CCl}$ & 0.784 & 0.503 & 1.223 & 0.284 & - & - & - & - \\
\hline ECOG & 1.521 & 0.853 & 2.713 & 0.155 & 1.349 & 0.737 & 2.467 & 0.331 \\
\hline Pathological stage & 1.749 & 0.818 & 3.740 & 0.150 & 1.196 & 0.501 & 2.859 & 0.687 \\
\hline $\begin{array}{l}\text { Perioperative therapy } \\
\text { (including chemotherapy } \\
\text { and radiotherapy) }\end{array}$ & 0.725 & 0.215 & 2.444 & 0.604 & - & - & - & - \\
\hline $\begin{array}{l}\text { Moderately differentiated } \\
\text { vs. poorly differentiated }\end{array}$ & 0.550 & 0.073 & 4.156 & 0.562 & - & - & - & - \\
\hline $\begin{array}{l}\text { Moderately differentiate } \\
\text { vs. well differentiated }\end{array}$ & 1.844 & 0.690 & 4.929 & 0.223 & - & - & - & - \\
\hline BMI $\left(k g / m^{2}\right)$ & 0.899 & 0.795 & 1.017 & 0.091 & 0.923 & 0.808 & 1.054 & 0.237 \\
\hline $\begin{array}{l}\text { Pathological adverse } \\
\text { features score }\end{array}$ & 1.551 & 0.749 & 3.211 & 0.238 & - & - & - & - \\
\hline $\begin{array}{l}\text { Closet surgical margin } \\
(\mathrm{mm})\end{array}$ & 1.003 & 0.910 & 1.105 & 0.952 & - & - & - & - \\
\hline Monocyte (\%) & 1.029 & 0.860 & 1.230 & 0.758 & - & - & - & - \\
\hline NLR & 1.080 & 0.908 & 1.286 & 0.383 & - & - & - & - \\
\hline
\end{tabular}

The age at diagnosis correlates with overall survival in the univariate COX regression analysis $(P=0.005)$; the factors of marginal significance include ECOG, pathological stage, BMI, and the depth of invasion. The multivariate COX regression analysis includes factors marginally suggesting association with survival outcome $(\mathrm{P}<0.2)$ in the univariate COX regression analysis. The age at diagnosis correlates with overall survival $(\mathrm{P}=0.032)$. $\mathrm{HN}-\mathrm{CCl}$, head and neck cancer comorbidity index; ECOG, the Eastern Cooperative Oncology Group performance status; BMI, body mass index; WBC, white blood cell; NLR, neutrophil-to-lymphocyte ratio. 
Table S3 Parameters of inflammation

\begin{tabular}{lc}
\hline Parameter & Mean (range, SD) \\
\hline WBC count $\left(\times 10^{3} / \mu \mathrm{L}\right)$ & $6.61(2.50-13.30,1.90)$ \\
Neutrophil $(\%)$ & $61.05(39.80-83.00,9.16)$ \\
Lymphocyte $(\%)$ & $26.26(6.00-52.80,8.63)$ \\
Monocyte (\%) & $8.81(4.40-17.60,2.31)$ \\
Neutrophil-to-lymphocyte ratio & $2.83(0.75-13.83,1.96)$ \\
Platelet-to-lymphocyte ratio & $139.09(36.18-360.94,67.99)$ \\
\hline
\end{tabular}

The parameters of inflammation include WBC count, neutrophil count, lymphocyte count, monocyte count, neutrophil to lymphocyte ratio, and platelet to lymphocyte ratio. WBC, white blood cell; SD, standard deviation.

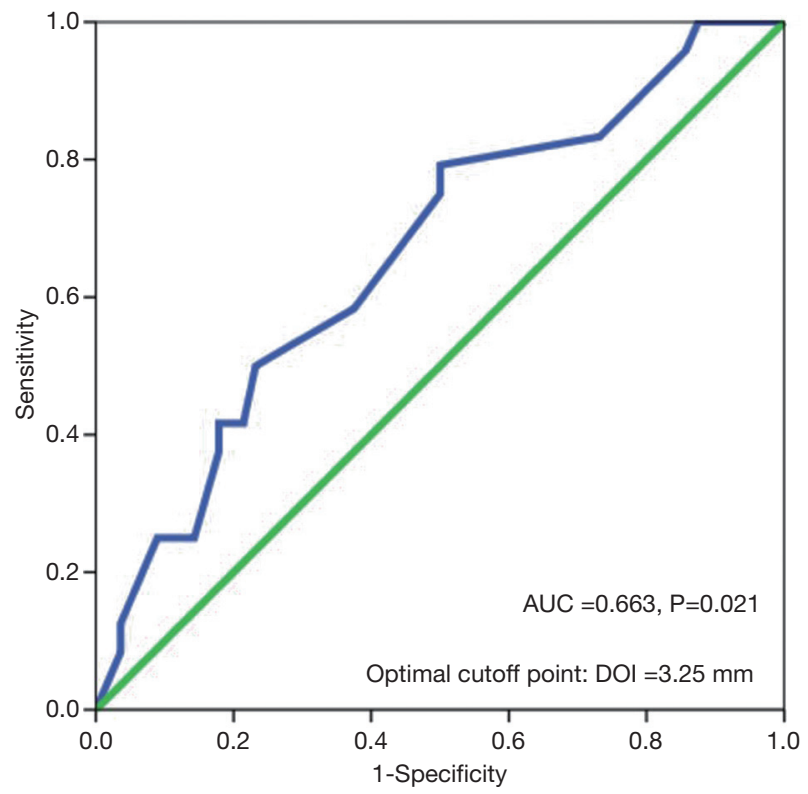

Figure S2 ROC curve analysis of depth of invasion (DOI) (mm). ROC curve analysis of depth of invasion was performed based on diseasefree survival. The AUC is 0.663 and the optimal cutoff point is $3.25(\mathrm{P}=0.021)$. ROC, receiver operating characteristic; AUC, area under the ROC curve.

Table S4 Disease-free survival of patients with DOI $<3.25 \mathrm{~mm}$ and DOI $\geq 3.25 \mathrm{~mm}$

\begin{tabular}{|c|c|c|c|c|}
\hline \multirow{2}{*}{$\begin{array}{l}\text { Depth of invasion } \\
\text { (DOI) }\end{array}$} & \multirow{2}{*}{$\begin{array}{c}\text { Mean disease-free } \\
\text { survival (years) }\end{array}$} & \multirow{2}{*}{ SD } & \multicolumn{2}{|c|}{$95 \% \mathrm{Cl}$} \\
\hline & & & Lower limit & Upper limit \\
\hline $\mathrm{DOI}<3.25 \mathrm{~mm}$ & 7.153 & 0.530 & 6.115 & 8.192 \\
\hline $\mathrm{DOI} \geq 3.25 \mathrm{~mm}$ & 6.569 & 0.678 & 5.239 & 7.898 \\
\hline Overall & 7.397 & 0.517 & 6.383 & 8.410 \\
\hline
\end{tabular}

Patients with $\mathrm{DOI} \geq 3.25 \mathrm{~mm}$ present decreased DFS. DFS, disease-free survival. 


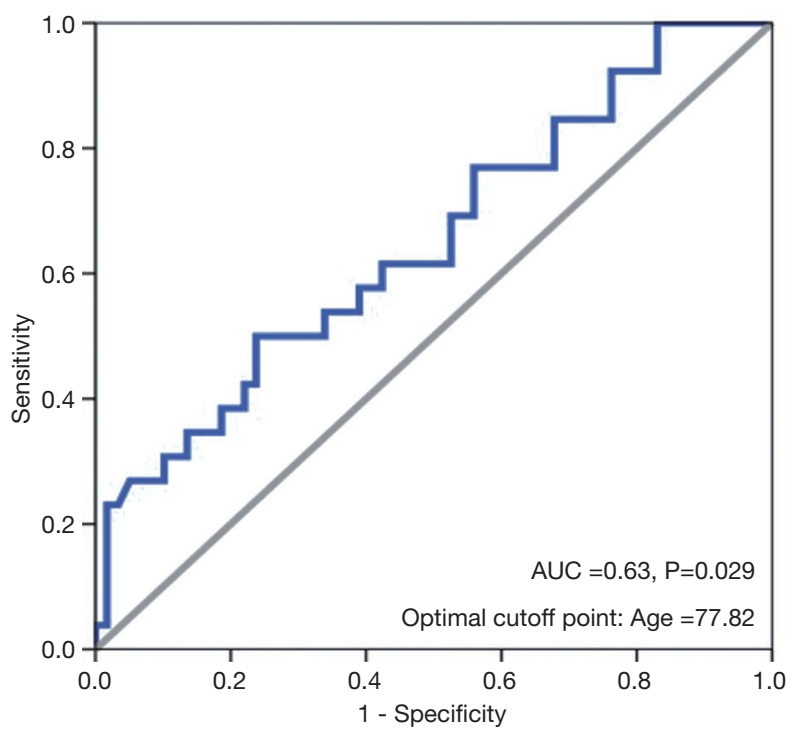

Figure S3 ROC curve analysis of age at diagnosis (years). ROC curve analysis of age was performed based on overall survival. The AUC is 0.63 and the optimal cutoff point is $77.82(\mathrm{P}=0.029)$. ROC, receiver operating characteristic; AUC, area under the ROC curve.

Table S5 Overall survival (OS) of patients with age $<77.82$ and age $\geq 77.82$

\begin{tabular}{lcccc}
\hline Age & $\begin{array}{c}\text { Mean overall survival } \\
\text { (years) }\end{array}$ & SD & 95\% Cl \\
\cline { 4 - 5 }$<77.82$ years & 8.858 & 0.640 & Lower limit & Upper limit \\
$\geq 77.82$ years & 6.095 & 0.875 & 4.604 & 10.112 \\
Overall & 8.108 & 0.562 & 7.007 & 7.809 \\
\hline
\end{tabular}

Patients in the "younger old" group of age between 70 and 77.82 years present better OS than the group of advanced age ( $\geq 77.82)$. SD, standard deviation; $\mathrm{Cl}$, confidence interval.

Table S6 Patients stratified by treatment and pathological adverse risk features

\begin{tabular}{lccc}
\hline $\begin{array}{l}\text { Number of pathological adverse } \\
\text { risk features }\end{array}$ & Surgery alone & $\begin{array}{c}\text { Surgery with perioperative } \\
\text { therapy }\end{array}$ & Overall \\
\hline 0 & 60 & 4 & $64(75.3 \%)$ \\
1 & 12 & 6 & $18(21.2 \%)$ \\
2 & 3 & 0 & $3(3.5 \%)$ \\
\hline
\end{tabular}

The number of patients with 0,1 and 2 pathological adverse risk features is 64 (75.3\%), $18(21.2 \%)$, and $3(3.5 \%)$, respectively. ${ }^{\dagger}$, pathological adverse risk features: extra-nodal extension, positive margins, perineural invasion, lymphovascular invasion.

Table S7 Survival analysis based on treatment and pathological adverse risk features

\begin{tabular}{|c|c|c|c|}
\hline Outcome & Treatment & Number of pathological adverse risk feature & $P$ value of log rank test \\
\hline \multirow{4}{*}{$\begin{array}{l}\text { Disease-free survival } \\
\text { (DFS) }\end{array}$} & \multirow[t]{3}{*}{ Surgery alone } & 0 versus 1 & 0.173 \\
\hline & & 0 versus 2 & 0.001 \\
\hline & & 1 versus 2 & 0.253 \\
\hline & $\begin{array}{c}\text { Surgery with perioperative } \\
\text { treatment }\end{array}$ & 0 versus 1 & 0.414 \\
\hline \multirow{4}{*}{$\begin{array}{l}\text { Overall survival } \\
\text { (OS) }\end{array}$} & \multirow[t]{3}{*}{ Surgery alone } & 0 versus 1 & 0.335 \\
\hline & & 0 versus 2 & 0.001 \\
\hline & & 1 versus 2 & $<0.001$ \\
\hline & $\begin{array}{c}\text { Surgery with perioperative } \\
\text { treatment }\end{array}$ & 0 versus 1 & 0.678 \\
\hline
\end{tabular}

